\title{
O PROTAGONISMO BRASILEIRO DIANTE DA DECLARAÇÃO DE TEERÃ
}

\section{The Brazilian leading role up to Tehran's declaration}

\author{
Camila Feix Vidal $^{1}$
}

\section{Introdução}

Recebida com ceticismo por diversos setores da mídia, da população e até mesmo da diplomacia brasileira, a Declaração de Teerã (acordo tripartite entre Turquia, Brasil e Irã datado de 17/05/2010) foi alvo de críticas que atribuíam a Luis Inácio Lula da Silva e Celso Amorim, então Presidente da República e seu chanceler, uma postura “megalomaníaca”, “anti-americanista” e “anti-sionista” (PINTO, 2012 e PECEQUILO, 2012). No âmbito internacional, no entanto, o documento foi recebido com otimismo, inclusive pela Agência Internacional de Energia Atômica (AIEA); a exceção foi a surpreendente recusa dos Estados Unidos, responsável pelo rechaço imediato da Declaração e por pressionar os demais membros do Conselho de Segurança da Organização das Nações Unidas (CSNU) a seguirem com o pacote de sanções ao Irã.

Assunto sensível e designado, até então, às grandes potências mundiais, a contenção do projeto nuclear iraniano pelas vias diplomáticas parecia, em fins de 2009, estar fadado ao fracasso. Desde a eleição de Barack Obama, a administração norteamericana buscava uma solução diplomática para o enriquecimento de urânio iraniano. A partir de início de 2009, os Estados Unidos juntamente com Rússia, China, Inglaterra, França e Alemanha (P5+1) lideraram diversos encontros políticos e estratégicos (esses com a presença da AIEA) com representantes do Irã, a fim de solucionar o impasse sobre o enriquecimento de urânio e o projeto nuclear iraniano. No entanto, as mediações

\footnotetext{
${ }^{1}$ Bacharel em Relações Internacionais pela Florida International University. Mestre e doutoranda em Ciência Política pela Universidade Federal do Rio Grande do Sul. E-mail: camilafeixvidal@gmail.com.
} 


\section{Conjuntura Austral}

foram infrutíferas. Como resultado, os P5+1 iniciaram, ainda fora do âmbito do CSNU, o processo de definição de quais sanções seriam, então, impostas a Teerã. Em maio de 2010, no entanto, Brasil e Turquia lograram a aceitação iraniana, tal como havia sido estipulada pelos P5+1 alguns meses antes. A Declaração de Teerã refletia fielmente todos os pontos solicitados pelos Estados Unidos e que haviam sido recusados pela administração Iraniana anteriormente. A diplomacia brasileira e a diplomacia turca haviam conseguido o que ninguém mais imaginava ser possível: um acordo, nos moldes do P5+1, com o Irã.

Estranhamente, o protagonismo brasileiro na mediação com o Irã, país até então sem laços estreitos com o Brasil, parece ser pouco estudado por acadêmicos brasileiros. Independente das percepções “negativas” sobre o acordo, a Declaração de Teerã significou um marco histórico tanto nas relações internacionais (nitidamente no relacionamento entre o “ocidente” e o Irã), como na diplomacia brasileira. Desssa maneira, o artigo proposto tem o objetivo de analisar o protagonismo brasileiro na mediação com o país persa em 2010 e que culminaria com a Declaração de Teerã, através de um estudo sobre a diplomacia brasileira de Lula.

Por meio de análise bibliográfica, documental e de conteúdo, se busca inferir que: o protagonismo brasileiro no caso da mediação com o Irã é reflexo tanto de padrões enraizados e típicos da diplomacia brasileira (“acumulado histórico” para Amado Cervo, 2008), bem como de fatores novos, caracterizados na própria política externa assertiva de Lula e Celso Amorim. A Declaração de Teerã só foi possível graças a essa combinação de tradição e inovação presente na diplomacia brasileira durante a presidência de Lula.

\section{O “acumulado histórico” da Política Externa Brasileira e a Diplomacia de Lula}

A base da diplomacia brasileira demonstra um continuum, caracterizado por determinados padrões de conduta presentes ao longo dos anos e já enraizados como parte permanente da política externa brasileira. Conforme Cervo (2008), esses padrões de conduta seriam responsáveis pela composição do “acumulado histórico" da diplomacia brasileira, tais como: autodeterminação; não-intervenção; solução pacífica 


\section{Conjuntura Austral}

de controvérsias; juridicismo; multilateralismo normativo; ação externa cooperativa e não-confrontacionista; parcerias estratégicas; realismo e pragmatismo; cordialidade oficial no trato com os vizinhos; desenvolvimento como vetor; e independência de inserção internacional.

Assim, ainda que cada presidência e chancelaria possam diferir na ênfase dada a determinados temas, regiões e problemas; e na maneira escolhida para seguir os objetivos amplos de política externa, a base que delimita e rege o comportamento da diplomacia brasileira é a mesma. Dessa maneira, mesmo mantendo ações políticas diferentes entre si, a "equidistância pragmática” de Getúlio Vargas, a "política externa independente” de Jânio Quadros e o “pragmatismo responsável” de Geisel, por exemplo, inserem-se no mesmo padrão atemporal da diplomacia brasileira caracterizado pela ênfase no desenvolvimento, autonomia, e ação externa cooperativa, entre outros padrões de acumulado histórico.

De acordo com Celso Amorim, a credibilidade e o reconhecimento internacional do Brasil é reflexo justamente desses princípios, enraizados na diplomacia brasileira, que guiam as ações de política externa:

"We are a peaceful country, one that abides by international law and
respects other countries' sovereign rights. We choose to settle our
disputes diplomatically- and we encourage others to act in the same
way. We see multilateralism as the primary means of solving
conflicts and making decisions internationally. We uphold Brazilian
interests with pragmatism, without renouncing our principles and
values. These characteristics of our foreign policy have been more or
less constant over time. Departures have been rare and short lived"
(AMORIM in RBPI, 2010, p.214).

A política externa empreendida durante a presidência de Lula, portanto, mantém os princípios basilares da diplomacia brasileira, impondo no nível das ações políticas práticas; porém, uma nova diplomacia caracterizada como mais “assertiva”. Dessa maneira, os objetivos típicos da política externa brasileira, tais como autonomia, desenvolvimento, e inserção internacional, são mantidos nessa presidência; difere, no entanto, das ações, preferências e percepções do sistema internacional empregadas em governos anteriores. Assim, o governo Lula "realizou mudanças de ênfases e de tonalidade em sua política externa (ajustes), buscando novas formas de inserção 


\section{Conjuntura Austral}

internacional para o país (mudanças de programa)” (VIGEVANI e CEPALUNI, 2007, p.7) ${ }^{2}$, enquanto mantinha as metas e objetivos amplos de política externa inalterados.

Caracterizada por “autonomia pela diversificação” (VIEGEVANI e CEPALUNI, 2007), em contraste com as anteriores “autonomia pela distância” e "autonomia pela participação", a política externa empreendida por Lula e Amorim buscava uma maior atuação brasileira no cenário internacional, reforma das instituições internacionais, e ênfase no relacionamento sul-sul. Nesse sentido, “diversificação” não significa simplesmente a busca de novos relacionamentos econômicos com diferentes e variados estados, mas também “implica (na) capacidade de intervenção em questões que não dizem respeito a interesses imediatos” (Ibidem, p.18), tal como metas imponentes, como um assento brasileiro no CSNU e maior protagonismo internacional na formulação de regras e diretrizes.

Ao final dos seus oito anos de mandato, percebe-se que o Brasil, efetivamente, assumiu um intenso protagonismo nas relações internacionais, característica de uma “diplomacia multilateral” (AMORIM, 2007): comanda a operação de paz no Haiti (MINUSTAH); formou o grupo “amigos da Venezuela” para lidar com a tensão política no país e com a oposição que se instaurou contra Hugo Chávez; liderou a formação do IBAS e dos BRICS; e esteve presente em regiões até então de pouca atuação brasileira, tal como a América Central, durante a deposição do então presidente da Honduras, no Oriente Médio (fez parte do grupo de diálogo sobre a paz entre Palestina e Israel) e, foco central do artigo aqui proposto, no Irã ${ }^{3}$.

Ainda que o multilateralismo já existisse e fizesse parte da diplomacia brasileira em governos anteriores, Lula lhe atribui uma nova ênfase e característica: De acordo com o tema e a conjuntura, se formula coalizões (geometria variável) para aumentar seu poder relativo e inserção internacional (VISENTINI e SILVA, 2010, RBPI):

"Brazil's multilateral relations during this government reached a new significance with the reinforcement of international coalitions and the

\footnotetext{
${ }^{2}$ Os autores usam o modelo de Hermann (1990) para analisar a política externa de Lula. Esse modelo caracteriza as mudanças na política externa em: pequenos ajustes, modificações de objetivos e de programas, e alterações amplas e fundamentais no comportamento dos países.

${ }^{3}$ Celso Amorim faz uma analise aprofundada do protagonismo do Brasil na arena global durante o mandato de Lula, indo além dos exemplos supracitados, no seu artigo publicado pela RBPI 2010.
} 


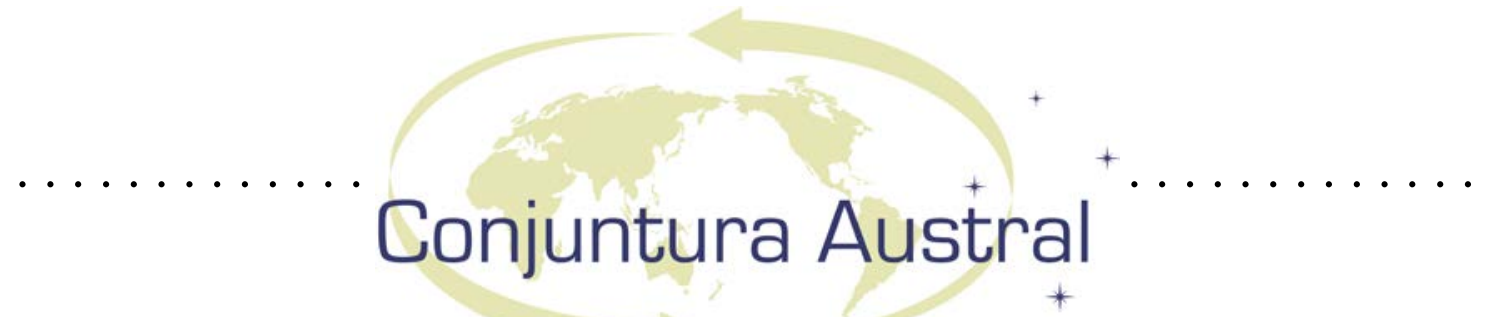

articulation with the country's new development model. The country has been using multilateral forums as a way to achieve international projection and support for its development project, highlighting bargaining aspects, variable geometry coalitions and strengthening of South-South cooperation” (Ibidem, p.71).

No caso do Irã, a diplomacia brasileira seguiu os mesmos padrões, princípios e objetivos que formam o seu "acumulado histórico", mas impôs, também, as novas características que seriam presentes durante o governo Lula, fazendo com que a mediação com o Irã seja um exemplo típico tanto de continuidade, como de inovação na política externa brasileira.

\section{O “congelamento do poder mundial”}

A busca por um sistema internacional efetivamente democrático em que o Brasil pudesse participar da formulação das diretrizes internacionais e ter maior inserção global é uma constante na política externa brasileira, em especial após a Segunda Guerra Mundial. Perpetua-se na visão da diplomacia brasileira ao longo dos anos, ainda que com falhas esporádicas, a noção de que o sistema internacional reflete um momento histórico já ultrapassado na qual as potências da primeira metade do século XX permanecem ditando as regras econômicas, políticas e de segurança internacional enquanto países e regiões emergentes possuem pouca ou nenhuma manobra decisória. Mais especificamente, haveria no âmbito internacional um "congelamento do poder mundial” (Araujo Castro, 1971).

O "congelamento de poder", tal como caracterizado por Araujo Castro, é refletido na adoção do Tratado de Não Proliferação Nuclear (TNP) de 1970 e motivo de rejeição pelo governo brasileiro durante quase três décadas. ${ }^{4}$ Segundo essa concepção, o TNP tem como base uma "teoria de diferenciação entre nações adultas e responsáveis e poderosas e nações não poderosas e, por isso mesmo, não responsáveis e não adultas” que "consagra o poder e é uma institucionalização sem disfarce da desigualdade entre os Estados" (CASTRO in BRIGAGAO e FERNANDES, 2012 p.79). De acordo com Castro, contrário a experiência histórica, a premissa fundamental do TNP seria de que o poder traz consigo moderação e responsabilidade; daí a necessidade de limitar o uso de

\footnotetext{
${ }^{4}$ O Brasil adere ao TNP em 1998 no governo de Fernando Henrique Cardoso.
} 


\section{Conjuntura Austral}

armas nucleares no cenário internacional, preservando o direito dos países que já as possuem (nações responsáveis) e proibindo novos países da sua posse (nações irresponsáveis): “o perigo é agora um atributo dos fracos e não um atributo dos fortes. Ao conferir poderes e prerrogativas especiais às nações que atingiram o status de adultas na era nuclear, esse tratado poderá acelerar em vez de impedir a corrida pelo poder" (Ibidem, p.79).

O TNP, portanto, seria apenas uma das inúmeras formas de congelamento do poder mundial (nesse sentido, o poder militar), podendo ainda ser destacado o congelamento de poder político, econômico, tecnológico e cientifico que adviria por conta desse tratado. Dessa maneira, o Brasil, “condenado à grandeza” (Ibidem, p.97) por conta da sua massa demográfica, composição étnica, ordenamento socioeconômico e, principalmente, por sua "incontida vontade de progresso e desenvolvimento", deveria recusar a adesão ao Tratado em questão:

"As soluções medíocres e pequenas não convêm nem interessam ao
Brasil. Temos de pensar grande e planejar em grande escala, com
audácia de planejamento; e isto simplesmente porque o Brasil, ainda
que a isso nos conformássemos, não seria viável como país pequeno
ou mesmo como país médio. Ou aceitamos nosso destino como um
país grande, livre e generoso, sem ressentimentos e sem preconceitos,
ou corremos o risco de permanecer a margem da história, como povo
e como nacionalidade” (Ibidem, p.98) ${ }^{5}$.
poder”, assim, serviu durante anos como justificativa da O “congelamento de poder”, assim, serviu durante anos como justificativa da recusa brasileira em assinar o TNP, considerando o Brasil tanto o seu projeto nuclear em desenvolvimento, como a própria estrutura do Tratado que concedia privilégios perpétuos a um seleto grupo de potências, obrigando o restante dos países a abdicar de tal aspiração. Ainda que o tenha ratificado em fins de 1990, o discurso de Araujo Castro contra a "institucionalização" da desigualdade internacional faz parte dos princípios enraizados na diplomacia brasileira e a partir dele que a política externa de Lula demonstra leniência com o projeto nuclear iraniano.

\footnotetext{
${ }^{5}$ É pertinente notar a semelhança do discurso de Araujo Castro e de Celso Amorim, esse último: “Temos consciência de que a afirmação dos valores e interesses brasileiros no mundo é - e sempre será - global em seu alcance. Sem entrar no mérito de saber se isso é uma vantagem ou uma desvantagem, o Brasil não é um país pequeno. Não tem e não pode ter uma política externa de país pequeno” (AMORIM, 2007, p.7).
} 


\section{Conjuntura Austral}

Mantendo as diretrizes e princípios da diplomacia brasileira tal como a ênfase na autonomia, não-ingerência, solução pacífica de controvérsia e a recusa ao “congelamento de poder”, a diplomacia de Lula cria novas características para a política externa brasileira, alem de reforçar as outras já presentes.

\section{A questão do Irã na percepção da diplomacia brasileira}

A mudança na diplomacia que se fez presente, durante o governo Lula, especificamente no caso do Irã, é típica dos ajustes por conta da mudança de governo, em função de uma nova percepção do sistema internacional, de diferentes ênfases e preferências no sistema internacional. Assim, esse governo impõe uma tendência mais “afirmativa” em determinadas questões, tal como nas de segurança nacional e internacional, ${ }^{6}$ em contraste com a tendência anterior "reativa” (VILLA e VIANA, RBPI, 2010). Nesse sentido, a diplomacia multilateral e afirmativa do Brasil na era Lula refletem alguns conceitos que seriam característicos dessas mudanças e que explicariam, assim como os princípios fundamentais da política externa brasileira, a atuação do Brasil na mediação com o Irã: “multilateralismo recíproco"; e nãoindiferença.

Com relação ao multilateralismo recíproco, a diplomacia brasileira, segundo Amado Cervo (RBPI, 2010, p.11) o utiliza em todas as áreas das relações internacionais, desde comércio à segurança: "the concept involves two presuppositions: the existence of rules to govern the international order, without which the power disparity will prevail in favor of the great powers; and the joint formulation of these rules, so that they will not favor the interests of some to the detriment of the interest of others”. Ainda segundo Cervo, essa concepção elimina duas “utopias” no entendimento da diplomacia brasileira: estabilidade hegemônica e a ligação necessária entre regime político e política externa. A rejeição da teoria da estabilidade hegemônica significaria a ênfase no multilateralismo internacional e a rejeição, pela diplomacia brasileira, de um sistema internacional baseado em único poder (Estados Unidos) e a consequente

\footnotetext{
${ }^{6}$ Internacionalmente se verifica a atuação do Brasil em diversas questões relativas à segurança internacional, tais como: Colômbia x Farc; Israel x Palestina; e Irã.
} 


\section{Conjuntura Austral}

subserviência dos outros estados a essa hegemonia. Com relação à segunda “utopia”, o multilateralismo recíproco crê que um regime político não necessariamente demonstra sequência lógica entre desenvolvimento, paz e justiça: "Liberal and democratic regimes operate toward these ends but may also operate in an opposite direction" (CERVO in RBPI, 2010, p12).

Já o principio de não-indiferença foi associado, conforme discurso do Ministro Celso Amorim em 2005, com a atitude brasileira de preocupação e solidariedade ante problemas e conflitos nacionais ou internacionais. Segundo Amorim:

"A diplomacia brasileira pauta-se pelo princípio da não-ingerência em
assuntos internos, consagrado em nossa carta. O Governo do
Presidente Lula tem associado à esse princípio básico uma atitude que
descrevemos como de "não-indiferença". Temos prestado nosso apoio
e solidariedade ativos em situações de crise, sempre que somos
solicitados e consideramos ter um papel positivo" (AMORIM in
MRE, 2007, p.20,21).
anar, ainda, que a política externa do governo Lula, ao manter as bases tradicionais da diplomacia brasileira, enfatiza alguns pontos, entre eles
a recusa ao congelamento do poder mundial. Observa-se a semelhança de discursos entre Celso Amorim e Araujo Castro (um exemplo já supracitado), e principalmente na percepção global defendida por Samuel Pinheiro Guimarães, então Secretário-Geral das Relações Exteriores. De acordo com o Guimarães, “A estrutura do sistema internacional pode ser descrita como formada por um reduzido núcleo de grandes potências econômicas que concentram em seu conjunto mais de $80 \%$ da produção, do comércio e da capacidade tecnológica e científica mundial” (GUIMARAES, 2005, p.246). Assim, como resultado, ocorre um "extraordinário processo de concentração de poder econômico, tecnológico, político, militar e ideológico” (Ibidem, p.251). No campo militar, especificamente, o diplomata sustenta que a concentração de poder é percebida “pela consolidação jurídica dos privilégios militares das grandes potências não só para desenvolver e deter o conhecimento e a produção de armas de destruição em massa, mas também para promover o desarmamento dos países da periferia” (Ibidem, p.251). Nesse sentido, o interesse norte-americano em deter o projeto nuclear iraniano, portanto, serviria a manutenção do "congelamento de poder mundial”, tal como defendido inicialmente por Araujo Castro e mantido por Guimarães. 


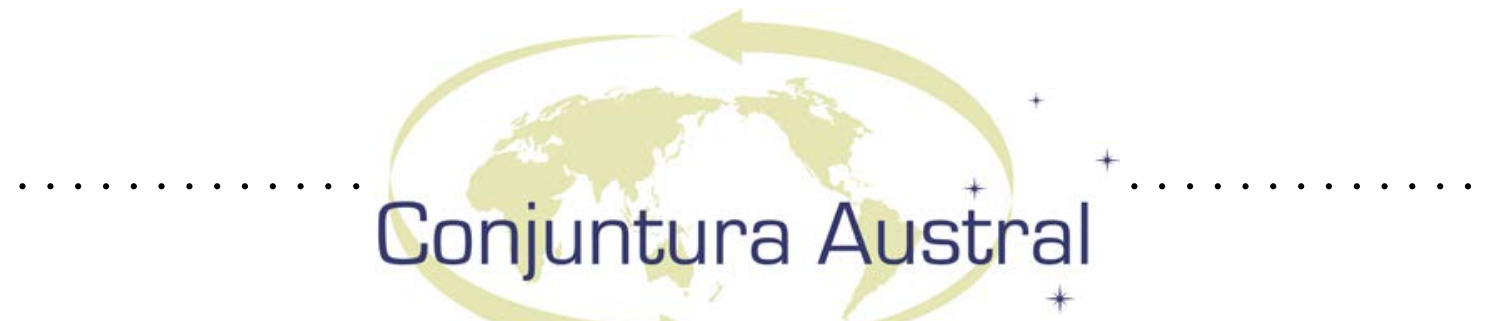

O envolvimento brasileiro na questão do Irã reflete, portanto, tanto os princípios mantenedores da diplomacia brasileira de recusa ao "congelamento de poder" e de ênfase na democratização dos organismos e estruturas internacionais, assim como as novas percepções e concepções da ordem mundial, oriundas da presidência de Lula, de ênfase no multilateralismo recíproco e do princípio de não-indiferença.

\section{A atuação brasileira na Declaração de Teerã}

A diplomacia de Lula, conforme já analisado, pautou-se pela diversificação de parcerias e pelo protagonismo no cenário internacional, enquanto mantinha as linhas basilares da política externa brasileira. O relacionamento com o Irã e a mediação brasileira e turca com esse país é um dos inúmeros exemplos que corroboram para essa afirmação.

Desde o início de seu mandato, o então presidente e o seu chanceler demonstraram apoio ao projeto nuclear iraniano, desde que para fins pacíficos. Sendo parte do TNP e defendendo a "tese de irreversibilidade dos compromissos internacionais de desarmamento e não-proliferação” (MRE, 2003 in MRE, 2007, p.304), o Brasil reconhece o direito iraniano de desenvolvimento e do uso da energia nuclear ${ }^{7}$, não devendo outros Estados (Estados Unidos, em particular) ingererirem num assunto interno e relativo à política doméstica do Irã. No pensamento da diplomacia brasileira, o simples fato de o regime político desse país ser diferente e não aliado aos Estados Unidos não daria o direito de ingerência externa ${ }^{8}$. Para a diplomacia brasileira, até que se prove o contrário, a política de desenvolvimento nuclear iraniano tem objetivos pacíficos e, portanto, não deveria ser motivo de sanções ou mesmo intervenções externas. Além disso, acreditavam os dirigentes brasileiros, a ingerência externa no caso de sanções, poderia ter um efeito "boomerang” no sentido de não só não deter o progresso nuclear iraniano, mas fomentá-lo. Ou seja, uma aproximação baseada no

\footnotetext{
${ }^{7}$ Segundo nota a imprensa pelo MRE em 23 de fevereiro de 2007: “O Governo brasileiro reconhece o direito do Irã ao desenvolvimento e uso da energia nuclear para fins pacíficos, consagrado no art. IV do Tratado de Não-Proliferação Nuclear (TNP)” (MRE, 2007, p.87).

${ }^{8}$ Para a diplomacia brasileira, o fato de Israel, Índia e Paquistão não serem assinantes do TNP e ainda assim receberem privilégios, auxílios e o próprio reconhecimento dos Estados Unidos enquanto países nuclearmente armados, enquanto um assinante do Tratado, como é o caso do Irã, é rechaçado; é uma contradição e um desrespeito a legitimidade do Tratado e ao próprio direito internacional.
} 


\section{Conjuntura Austral}

confronto aumentaria os incentivos iranianos para desenvolvimento de um projeto nuclear não pacífico para defesa própria.

A mediação brasileira na questão iraniana retoma e aprofunda várias das linhas basilares da diplomacia brasileira, tais como: busca pela solução pacífica e diplomática em conflitos; recusa à ingerência externa; respeito ao jurisdicismo; e, ultimamente, a recusa pelo “congelamento de poder” tal como expressado quatro décadas atrás por Araujo Castro. De acordo com o então ministro Celso Amorim:

"O poder militar ainda se encontra muito concentrado. O fosso que separa países com capacidade diferente de defesa repercute no plano político, gera corridas por armamentos e contribui para criar instabilidade em diversas regiões” (AMORIM, 2008 in MRE, 2010, p.227).

É importante lembrar, ainda, que Celso Amorim participava do CSNU como representante brasileiro na década de 1990, quando sanções foram impostas ao Iraque. Naquele momento, não houve mudança significativa ou perceptível pelas lideranças iraquianas, sendo o preço das sanções pago pela população mais pobre do país. Ainda que não explícito, ao que tudo indica a diplomacia brasileira teve receio de a escolha pelas sanções serem um meio para enfraquecer o regime político iraniano, e "inimigo" do ocidente, e que serviria, em última análise, aos objetivos militares, econômicos e políticos dos Estados Unidos na região persa e do Oriente Médio. De acordo com Celso Amorim:

\footnotetext{
"Most of the times, sanctions affect the most vulnerable people. They have no effect whatsoever on the leadership. Moreover, after sanctions devasted Iraq, and (...) contributed to the death of 500,000 Iraqi children in the period 1990-2000, the US proceeded to invade the country in a war that has yet to come to a full conclusion" (AMORIM in PARSI, 2012, p.174).
}

A dificuldade enfrentada pelo Irã refletia, em grande parte, a dificuldade brasileira durante a década de 1970 com o seu próprio programa nuclear e a forte oposição que se seguiu pelos Estados Unidos. Além disso, o Brasil acreditava que as possíveis sanções impostas ao regime iraniano, no caso de fracasso de uma solução pacifica, poderiam abrir precedentes para a intervenção em países ricos em urânio e que praticam o seu enriquecimento, tal como no caso do Brasil.

De acordo com Trita Parsi: 


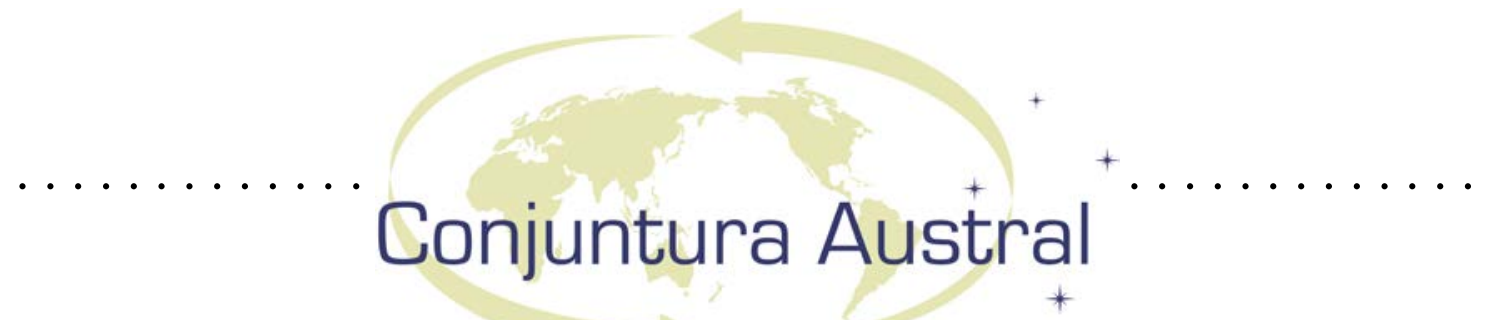

\begin{abstract}
" At the heart of the matter was Brazil's own nuclear program, which was more advanced than the Iranian program and did not receive as much attention from IAEA inspectors. Moreover, the Brazilians feared that UN actions on the Iranian nuclear file would set a precedent that defined enrichment of uranium as a military activity" (PARSI, 2012, p.174).
\end{abstract}

A mediação do Brasil na questão do Irã, refletia, portanto, objetivos muito maiores que um simples "protagonismo” brasileiro em função de uma possível vaga no CSNU. Ainda que esse fosse um objetivo contundente da administração Lula e importante na avaliação do envolvimento brasileiro na questão iraniana, o Brasil buscava demonstrar uma lógica contraditória e injusta de um sistema que privilegia as grandes potências, tal como já enfatizava Araujo Castro, e penalizava as nações de médio porte que buscavam sua autonomia e desenvolvimento próprio. Para Trita Parsi:

"While Brazil's position could superficially be interpreted as a challenge too America's leadership, Brazilian decision makers viewed it as the effort of 'an emerging country with a long history of frailty and dependence' to seek protection and hedge 'against great power use of international norms to impose their will on weaker nations'” (PARSI, 2012, p.177).

Desde o início de seu mandato, Lula buscou maior aproximação com o Irã. Junto com 300 empresários brasileiros, o então presidente visitou o país e recebeu, também, a visita do representante iraniano em Brasília. A aproximação com esse país, no entanto, centrava-se em Celso Amorim que, em novembro de 2009 visita Teerã por duas vezes em menos de 10 dias. O objetivo das visitas, no entanto, era de estreitar laços políticos e econômicos entre os países, sem o interesse, imediato ao menos, na questão do projeto nuclear iraniano.

A mediação concertada entre Brasil e Turquia com relação ao Irã, só iria ser coordenada em início de 2010 quando ambos os países, então presentes no CSNU como membros não permanentes, tomaram consciência dos mútuos esforços de aproximação com Teerã. Concomitante, ambos os dirigentes brasileiros e turcos se sentiam frustrados com a imposição de sanções ao Irã, considerando essa tática como uma "prematurely aborted diplomacy” (PARSI, 2012) ${ }^{9}$.

\footnotetext{
${ }^{9}$ A Turquia já havia se oferecido para mediação entre Estados Unidos e Irã logo apos a eleição de Obama em 2008 (PARSI, 2012).
} 


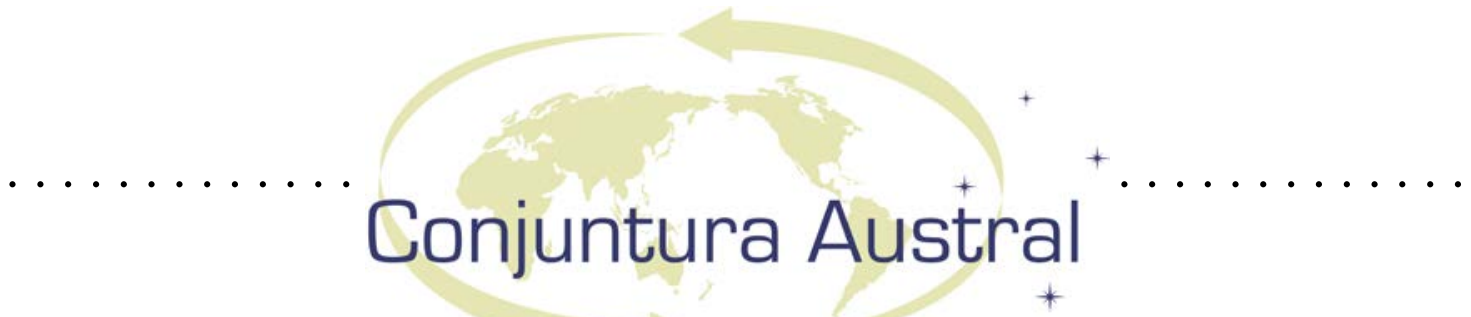

Em abril de 2010, líderes mundiais se encontrariam em Washington para um "Nuclear Summit" conduzido por Obama. Na ocasião, Erdogan (representante turco) e Lula contaram com o apoio do presidente norte-americano e do presidente francês para iniciarem uma mediação com o país persa: “After the Summit, both the French and the Americans framed Lula's upcoming state visit to Iran as the last chance for diplomacy” (PARSI, 2012, p.184) ${ }^{10}$. Em 20 de abril, Obama entregava uma carta a Lula e outra para Erdoban (iguais em substancia) em que solicitava o cumprimento de três pontos específicos, por parte do Irã: a) quantidade de urânio (1.200 kg); b) tempo (entrega imediata por parte do Irã, recebendo o urânio enriquecido um ano depois); e c) lugar (um "escrow" na Turquia). A carta ainda solicitava que o Irã enviasse a resposta diretamente e por escrito a AIEA. Levando a carta em mãos, as delegações de Brasil e Turquia se dirigiram a Teerã.

Durante as negociações, de acordo com Parsi:

"The issue of trust was a constantly recurring one - not only as it related to Iran's mistrust of the US or its fear that Turkey could be susceptible to pressure from Washington to violate the terms of its escrow, but also the fear that Turkey ad Brazil would fail in securing American acceptance of the deal (...) to reassure the Iranians, the Turks showed them Obama's letter to Erdogan and made the case that they had Washington's interest in the deal in writing. This proved decisive in convincing the Iranians to agree to the American parameters of the swap deal” (PARSI, 2012, p.189).

No terceiro dia de conversas, os dirigentes iranianos aceitavam os termos propostos por Brasil e Turquia, os mesmos que haviam rejeitado oito meses antes em Viena, então quando da mediação dos P5+1. Apesar de toda a descrença e dificuldade, Brasil e Turquia lograram, em alguns dias e por conta de intensa diplomacia, o que as grandes potências não conseguiram durante anos ${ }^{11}$.

A Declaração de Teerã, assinada por Ahmadinejad, Amorim e Erdogan em 17 de maio de 2010, refletia fielmente os três pontos que constavam na carta de Obama, assim como na tentativa de mediação pelos P5+1 em Viena alguns meses antes. Tal como

\footnotetext{
${ }^{10}$ Nas palavras de Sarkozy: "We've agreed with president Lula that this is the last chance, last-resort and last-chance initiative, and it has to happen very swiftly. It has to fit in with the timetable I presented to Iran, in other words, April or May" (SARKOZY, 2010, apud PARSI, 2012, p.184).

${ }^{11}$ De acordo com Parsi (2012), o tempo em negociações com Teerã gasto por Brasil e Turquia entre fins de 2009 e maio de 2010, superou o tempo gasto por todos os P5+1 juntos desde 2008.
} 


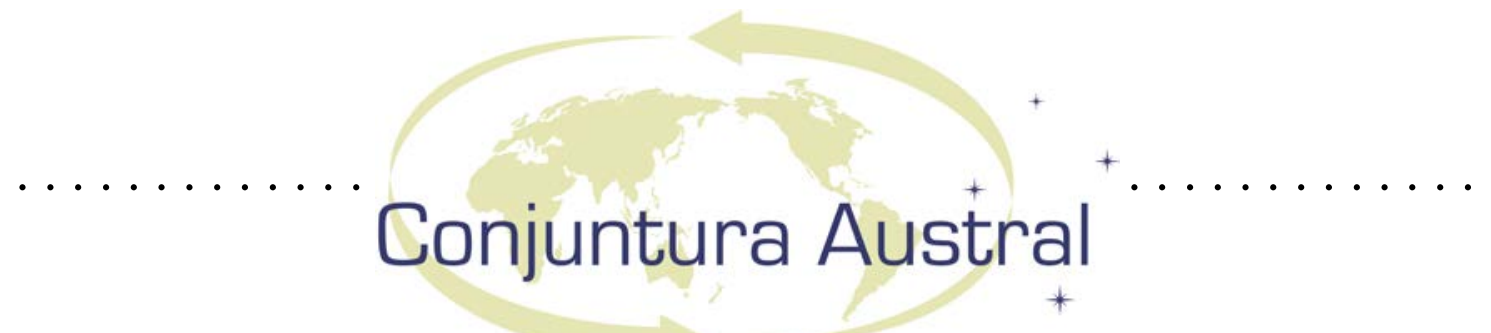

solicitado, o Irã concordava em depositar imediatamente 1.200 kg de urânio levemente enriquecido (LEU) na Turquia em troca de combustível nuclear para o Reator de Pesquisas de Teerã, ainda que esse combustível demorasse um ano para ser recebido. $\mathrm{O}$ governo iraniano aceitava, ainda, a última condição dos Estados Unidos: em 19 de maio de 2010, os dirigentes iranianos enviavam a Declaração, assinada pelos três países, para a AIEA, se comprometendo, assim, formalmente com os termos estabelecidos (DECLARACAO DE TEERA, 2010).

Imediatamente rechaçada pelos Estados Unidos em função de pressões internas e externas, a Declaração de Teerã não foi aceita por esse país, que prosseguiu com as reuniões no CSNU sobre a implementação de sanções, impostas alguns dias depois sem o aval de Turquia e Brasil por razoes óbvias ${ }^{12}$. Ao que tudo indica, os países do P5+1 foram “pegos de surpresa” com o anúncio da Declaração, já que esperavam a recusa, novamente, do Irã. Tendo sua posição “diplomática” questionada e em função das mais variadas pressões e do custo político com relação aos ouros membros do $\mathrm{P} 5+1$, os Estados Unidos continuaram a liderar as reuniões em torno das possíveis sanções a serem impostas ao Irã ${ }^{13}$. Alegando que a quantidade de LEU, tal como previamente estipulada em 1,200 kg já não era mais suficiente para deter o projeto nuclear iraniano, as sanções foram impostas ${ }^{14}$. Ao invés de deter o projeto nuclear iraniano, no entanto, essas tiveram o efeito “boomerang” alertado por Celso Amorim anteriormente: em

\footnotetext{
${ }^{12}$ A Resolução 1929 foi aprovada com o voto contrário de Turquia e Brasil e a abstenção de Líbano. De todas as sanções aprovadas contra o Irã na ONU, essa foi a que teve o mais fraco apoio dos países parte do CSNU (PARSI, 2012, p. 204) e a única vez em que o Brasil votou contra uma proposta aprovada no CSNU (AMORIM, 2010).

${ }^{13}$ De acordo com o então diretor da AIEA, Mohamed El-Baradei: "it seems that they could not take yes for an answer" (EL-BARADEI apud AMORIM, 2010, p.224).

${ }^{14}$ Para Parsi , Estados Unidos, França e Inglaterra teriam pressionado por sanções qualquer que fosse $o$ resultado da Declaração de Teerã: "there was never a question of the Tehran Declaration affecting the sanctions resolution” (PARSI, 2012, p.195). A surpresa foi a aceitação das sanções, mesmo com o sucesso da Declaração de Teerã, de Rússia e China. Ao que tudo indica, a pressão exercida pelos Estados Unidos foi o contribuinte principal para a imposição de sanções: "absent US pressure, however, it is not clear that Russia, China and many of the EU states wold have joined Washington in rejecting the deal” (Ibidem, p.196).
} 


\section{Conjuntura Austral}

2012, o Irã parece estar muito mais próximo e propenso a construir armas nucleares, do que em $2010^{15}$ (PARSI, 2012).

Ao que tudo indica a veemente recusa norte-americana em aceitar o acordo que eles próprios haviam redigido se deve a pressões republicanas no Congresso norteamericano, ao lobby doméstico pró-Israel, e as pressões de Israel e dos aliados árabes, em especial a Arábia Saudita. É importante mencionar o contexto político difícil em que o presidente dos Estados Unidos se encontrava no momento em que a Declaração foi aceita pelo Irã. Ainda que sob o controle de democratas, o Congresso norte-americano encontrava dificuldades em aprovar diversas propostas encaminhadas pelo Executivo, entre elas a reforma da saúde (Obamacare), por conta da oposição enfática dos Republicanos. Dessa maneira, ainda que Obama demonstrasse um interesse em maior diálogo e acordos com o Irã, tal como expressado antes da sua posse, a administração democrata sentia-se pressionada por diversos setores internamente, dentre eles os Republicanos mais conservadores e o grupo de lobistas pró-Israel, resposáveis por barrar as propostas de reforma da saúde; e, externamente, o lobby e pressão advinda por inimigos do Irã e aliados estratégicos dos Estados Unidos no Oriente Médio, entre eles, Israel e Arábia Saudita. De acordo com Parsi, “any nuclear deal that came before a new round of sanctions would complicate the Obama administration's domestic challenges. A deal without punishment - even a good deal - simply would not be enough” (PARSI, 2012, p.209). Assim, a recusa norte-americana em aceitar a Declaração de Teerã devese à necessidade de satisfazer setores descontentes facilitando, assim, a passagem pelo Congresso de propostas e iniciativas internas, enquanto se mantém a confiança de antigos e estratégicos aliados externos em uma região importante para os Estados Unidos, tal como o Oriente Médio.

A rejeição enfática norte-americana à Declaração de Teerã, no entanto, acabou por fomentar, no Brasil, críticas de setores oposicionistas do governo que já vinham demonstrando ceticismo referente à política externa desenvolvida por Celso Amorim. De certa maneira, o acordo tripartite foi exposto por esses setores como um fracasso, na

\footnotetext{
${ }^{15}$ Uma semana apos o CSNU impor o terceiro “round” de sanções no Irã, o governo iraniano anunciou que construiria um novo reator nuclear” (PARSI, 2012, p.210).
} 


\section{Conjuntura Austral}

medida em que não foi aceito pelos Estados Unidos, sendo ainda utilizado como um exemplo de uma política externa caracterizada como "megalomaníaca” e "antiamericanista” que prejudicava os interesses brasileiros no âmbito externo, portanto, não pragmática. É interessante notar que essas críticas fizeram-se mais visíveis justamente por ser esse (2010) um ano de eleições no Brasil. Aliada a outras críticas no âmbito de direitos humanos, por exemplo, diversos setores políticos e da mídia usaram o exemplo do "fracasso" da Declaração como evidência de um suposto mau direcionamento da política externa brasileira naquele momento sem, entretanto, evidenciar os motivos da recusa norte-americana, bem como as pressões internas e externas sofridas pela administração democrata em um ambiente doméstico instável.

O acordo com o Irã não tinha a pretensão, na concepção de Brasil e Turquia, de resolver todos os problemas referentes ao projeto nuclear iraniano. Ainda assim, era um primeiro e importante passo para futuras negociações e, principalmente, criava as condições para maior confiança entre as partes, em especial, entre os Estados Unidos e o governo persa. Dessa maneira, a Declaração de Teerã reflete o sucesso e o protagonismo da diplomacia brasileira. Junto com a Turquia e baseada em tradições e bases sólidas, a diplomacia da "não-indiferença” e do "multilateralismo recíproco" de Lula e Celso Amorim foi capaz de acordar um primeiro e único documento com o Irã relacionado ao seu projeto nuclear. Essa realização única para as relações internacionais só foi possível por conta do "acumulado histórico" da diplomacia brasileira, assim como a percepção, astúcia e crença do governo brasileiro de uma atuação assertiva, global e solidária no cenário internacional.

De acordo com Celso Amorim (2010), os motivos de sucesso que culminaram na Declaração são vários: tanto o Brasil como a Turquia são países em desenvolvimento com boas relações com o Irã; o Brasil é membro do G15, um grupo de países em desenvolvimento bem visto pelos dirigentes iranianos; a Turquia esta localizada no Oriente Médio e é uma importante nação islâmica na região; ambos os países não são nuclearmente armados; e, uma importante contribuição, tanto o Brasil como a Turquia mantiveram o diálogo com o Irã em um patamar de respeito mútuo, não assumindo de antemão que o programa nuclear iraniano seria usado com finaliade militar. 


\section{Conjuntura Austral}

A atmosfera característica presente nas negociações com o Irã era de respeito: a diplomacia estava sendo conduzida pelas bases da igualdade e sem preconceitos com foco na resolução de conflito e não na coerção. Além disso, tanto Turquia como Brasil não pouparam tempo ou disposição para manter uma negociação ampla que englobasse setores diversos do governo iraniano como: parlamento iraniano, escritório do líder supremo e diversos centros políticos e facções (PARSI, 2012), permitindo maior entrosamento e confiança entre as partes.

Indo mais além, a proeza alcançada pelo Brasil, especificamente, se sustenta na credibilidade advinda da sua tradição diplomática. Característica típica da diplomacia brasileira, o seu “caráter negociador” e a busca por soluções pacíficas em controvérsias, bem como o respeito ao jurisdicismo, remonta a era colonial e tem seu ápice na gestão de Rio Branco (1902-19012) quando grande parte dos limites brasileiros foi consolidado através de negociações. É importante notar, ainda, as diversas mediações lideradas pelo Brasil a partir dessa época e, em especial, na América Latina; além das missões de paz que envolvem a presença brasileira. Segundo Sergio Aguilar, a diplomacia brasileira através das várias missões de paz da qual o país fez parte "procura tratar a população do host country com respeito, entendendo que, durante as operações, não está lidando com um inimigo, mas sim com um povo de uma região onde a segurança, dentre outros aspectos, foi negligenciada em razão do conflito" (AGUILAR in BRIGAGAO e FERNANDES, 2012, p.218).

A própria diversidade religiosa e étnica, existente no Brasil, onde convivem pacificamente diferentes raças e religiões perpetua-se no cerne na diplomacia brasileira, permitindo o respeito a indivíduos, regimes e regiões diferentes. No caso do Irã, além do “caráter negociador” brasileiro; o respeito e o tratamento igualitário e não confrontativo para com esse país, teve importância mister para uma maior confiança entre as partes, o que, por sua vez, percebe-se, foi um fator fundamental na conclusão do acordo.

Outra importante base da diplomacia brasileira: a ação externa cooperativa e não confrontacionista é refletida na "cordialidade oficial no trato com os vizinhos" e no relacionamento harmonioso do Brasil e demais países do globo. Sem conflitos ou 


\section{Conjuntura Austral}

hostilidades com relação ao Irã, a diplomacia brasileira pode legitimar o seu papel de mediadora entre dois países sabidamente hostis entre si: Irã e Estados Unidos. Assim, uma diplomacia, tal como a brasileira, que se apresenta imparcial e isenta em relação ao conflito já existente, e que mantêm respeito genuíno ao pais mediado, tem grandes chances de sucesso na sua mediação.

Por último, a ênfase na autodeterminação, na não intervenção externa e no multilateralismo normativo são características constantemente presentes na diplomacia do Brasil, tendo como exemplo mais típico a recusa brasileira durante anos ao TNP nas bases de um provável "congelamento de poder mundial”. A busca pela autodeterminação e pela não intervenção significa, também, o respeito a essas características com relação a outros países. Nesse sentido, a percepção brasileira de respeito ao projeto nuclear iraniano, desde que para fins pacíficos; assim como a recusa ao “congelamento de poder”, reflete a ênfase brasileira de princípios já enraizados na diplomacia brasileira.

Assim, através de respeito mútuo; de uma política externa "ativa e altiva” caracterizada por Celso Amorim e Lula; e de tradições diplomáticas bem definidas que legitima o Brasil a condição de negociador, criou-se uma atmosfera de confiança entre as partes, ausente nas negociações anteriores entre P5+1 e Irã, e que viria a ser essencial para o sucesso do acordo.

\section{Conclusão}

Recebida com grande otimismo por diversos países e autoridades importantes, entre eles o então diretor da AIEA e o Secretário Geral da ONU Ban Ki-Moon ${ }^{16}$, a Declaração de Teerã é ainda válida, haja visto que nenhum dos países, nem mesmo o Irã, a denunciou, podendo, serem retomadas as negociações a qualquer momento ${ }^{17}$. No entanto, uma importante oportunidade se perdeu. As sanções impostas ao Irã e a

\footnotetext{
${ }^{16}$ Segundo Ban Ki-moon, a Declaração de Teerã foi uma "important initiative in resolving international tensions over Iran’s nuclear program by peaceful means” PARSI, 2012, P.192).

${ }^{17}$ De acordo com Leonencio Nossa e Gustavo Chacra (2012), Brasil e Turquia iniciaram novos diálogos, em fins de setembro de 2012, visando a retomada da Declaração de Teerã, dessa vez com o apoio direto da Suécia.
} 


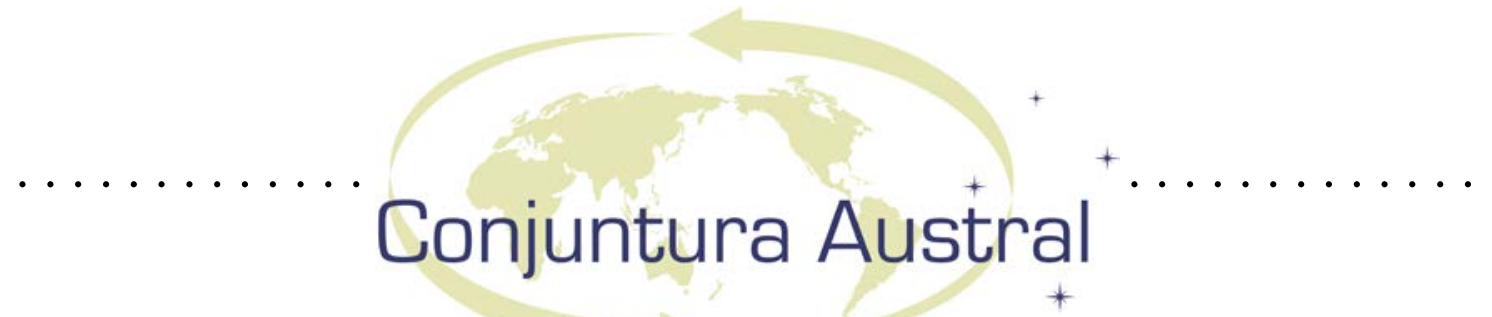

rejeição imediata dos Estados Unidos ao acordo tripartite significaram não só um retrocesso no diálogo das grandes potências com o Irã, como também, e ao contrário do que afirmou a Secretária de Estado Hilary Clinton em 2010, a não aceitação do acordo propiciou um "mundo mais perigoso" e propenso a ações confrontativas entre Irã e Estados Unidos ${ }^{18}$.

Ao contrário do que foi amplamente difundido em alguns setores da mídia e figuras diplomáticas descontentes com a política externa de Lula, a Declaração de Teerã não foi fruto de um "voluntarismo exagerado" do então presidente e de Celso Amorim, mas foi, sim, um exemplo de sucesso de ação diplomática que concilia aspectos tradicionais típicos da política externa brasileira, os enfatizando, inclusive; e inovações caracterizadas pela diplomacia “ativa e altiva” baseada na não-indiferença e no multilateralismo recíproco. O caso da mediação com o Irã, portanto, é um exemplo importante de sucesso diplomático brasileiro e que caracteriza o "acumulado histórico" da diplomacia juntamente com a inovação recente proposta pelo governo Lula, condizente com a atual época de globalização e com o crescente papel econômico e político brasileiro nas relações internacionais.

A globalização, a multipolaridade e a emergência de novos atores, temas e conflitos no sistema internacional propicia novos relacionamentos e oportunidades até então ausentes para o Brasil. Por conta de seu crescimento econômico e estabilidade política, o país pode, hoje, alcançar um protagonismo internacional. Obviamente esse protagonismo vincula-se com as nossas credenciais de país pacifico cuja ênfase é dada sempre na solução pacífica de controvérsias, e nas bases sólidas da nossa diplomacia.

Não se advoga, aqui, no entanto, que o governo brasileiro deve engajar-se em diferentes conflitos e em regiões distantes do globo a partir de agora. O que se buscou fazer nesse artigo foi uma análise mais aprofundada de um tema que não recebeu a devida atenção e reconhecimento tanto por parte da mídia como por parte das universidades. Assim, explicitada nesse estudo é a noção de que a Declaração de Teerã

\footnotetext{
${ }^{18}$ Segundo Trita Parsi, uma semana após a divulgação da Declaração de Teerã, “Clinton raised the rhetorical volume even further, claiming that Turkey and Brazil's efforts had made 'the world more dangerous'” (PARSI, 2012, p.194).
} 


\section{Conjuntura Austral}

foi um acordo importante e louvável nas relações internacionais e na historia da política externa brasileira. Através desse único exemplo, o Brasil pode ressaltar as características tradicionais da nossa diplomacia, bem como a inovação trazida pela política externa de Lula, demonstrando uma convivência harmoniosa entre tradição e inovação na diplomacia brasileira. Por fim, o acordo com o Irã pode enfatizar, domesticamente e internacionalmente, a credibilidade, o respeito, a neutralidade e a legitimidade da nossa diplomacia; características conquistadas ao longo de anos e transmitidas, hoje, aos demais países.

\section{REFERÊNCIAS}

AGUILAR, Sérgio. Uma Cultura Brasileira de Missões de Paz. In BRIGAGÃO, Clóvis e FERNANDES, Fernanda (orgs.). Diplomacia Brasileira para a Paz. Brasília: Funag. 2012.

AMORIM, Celso. Discurso por ocasião da cerimônia de transmissão do cargo de Secretário-Geral das Relações Exteriores. In: SILVA, Luis Inácio Lula da, AMORIM, Celso e GUIMARÃES, Samuel Pinheiro. A Política Externa do Brasil. Brasília: IPRI/Funag. 2003.

A Diplomacia Multilateral do Brasil. Brasília: Funag. 2007.

. Brazilian Foreign Policy under President Lula (2003-2005): an overview. RBPI - Revista Brasileira de Política Internacional. Ano 53, Special, 2010.

CASTRO, Araujo. O pensamento de Araujo Castro. In BRIGAGÃO, Clóvis e FERNANDES, Fernanda (org.). Diplomacia Brasileira para a Paz. Brasília: Funag. 2012.

CERVO, Amado Luiz. Inserção Internacional: Formação dos conceitos brasileiros. São Paulo: Saraiva. 2008.

CHACRA, Gustavo e NOSSA, Leonencio. Brasil e Turquia avaliam retomar pacto da era Lula sobre programa iraniano. Estadão. 25/09/2012. Disponível em: 


\section{Conjuntura Austral}

http://www.estadao.com.br/noticias/impresso,brasil-e-turquia-avaliam-retomar-pactoda-era-lula-sobre-programa-iraniano-,935321,0.htm. Acessado em 30/09/2012.

DECLARAÇÃO DE TEERÃ. 2010. Disponível em: http://www.itamaraty.gov.br/salade-imprensa/notas-a-imprensa/carta-aos-membros-do-conselho-de-seguranca-dasnacoes-unidas. Acessado em 10/10/2012.

GUIMARÃES, Samuel Pinheiro. Desafios Brasileiros na Era dos Gigantes. Rio de Janeiro: Contraponto. 2005.

MRE - Ministério das Relações Exteriores. Repertório de Política Externa: Posições do Brasil. Brasília: Funag. 2007.

MRE - Ministério das Relações Exteriores. Repertório de Política Externa: Posições do Brasil (2008-2009). Brasília: Funag. 2010.

PARSI, Trita. A Single Roll of the Dice: Obama's diplomacy with Iran. Yale University Press. 2012.

PECEQUILO, Cristina Soreanu. As Relações Brasil-Estados Unidos. Belo Horizonte: Fino Traço. 2012.

PINTO, Felipe Flores. O acerto da política iraniana de Lula. Carta Capital, novembro 2012. Disponível em: http://www.cartacapital.com.br/internacional/o-acerto-da-politicairaniana-de-lula/. Acessado em 22/11/2012.

SILVA, André Luiz Reis da e VISENTINI, Paulo G. Fagundes. Brazil and the Economic, Political, and Environmental Multilateralism: the Lula years (20032010). RBPI - Revista Brasileira de Política Internacional. Ano 53, Special, 2010.

VIGEVANI, Tullo e CEPALUNI, Gabriel. A Política Externa de Lula da Silva: a estratégia da autonomia pela diversificação. Contexto Internacional, Volume 29, No. 2, Julho-Dezembro 2007. Disponível em:

http://www.scielo.br/scielo.php?script=sci_arttext\&pid=S0102-85292007000200002.

Acessado em agosto, 2012.

VILLA, Rafael Antonio Duarte e VIANA, Manuela Trindade. Security Issues during Lula's administration: from the reactive to the assertive approach. RBPI - Revista Brasileira de Política Internacional. Ano 53, Special, 2010.

Artigo recebido dia 25 de fevereiro de 2013. Aprovado em 30 de março de 2013. 


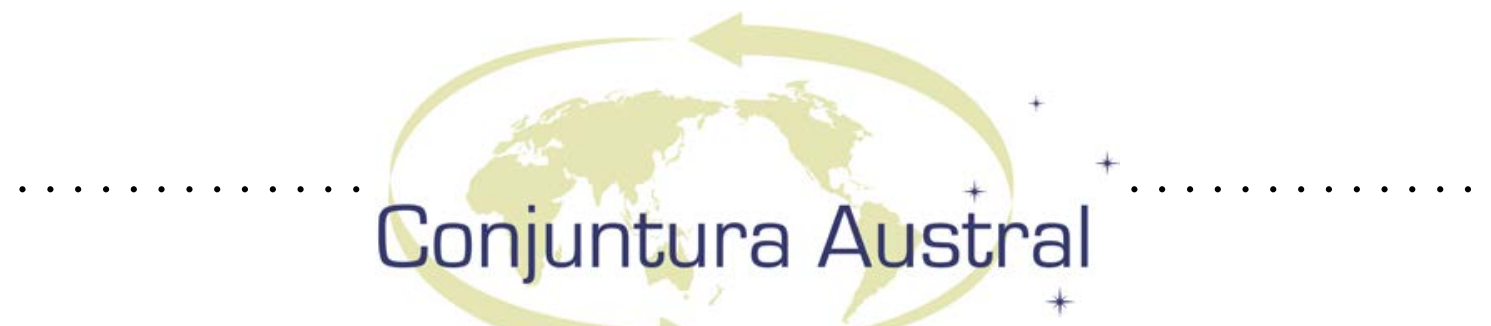

\title{
RESUMO
}

O artigo proposto tem o objetivo de analisar o protagonismo brasileiro na mediação com o Irã em 2010 e que culminaria com a Declaração de Teerã, através de um estudo sobre a diplomacia brasileira de Lula. Por meio de análise bibliográfica, documental e de conteúdo, se busca inferir que: o protagonismo brasileiro no caso da mediação com o Irã é reflexo tanto de padrões enraizados e típicos da diplomacia brasileira ("acumulado histórico" para Amado Cervo, 2008), bem como de fatores novos, caracterizados na própria política externa assertiva de Lula e Celso Amorim. A Declaração de Teerã só foi possível graças a essa combinação de tradição e inovação presente na diplomacia brasileira durante a presidência de Lula.

\section{PALAVRAS-CHAVE}

Declaração de Teerã, Brasil, Irã.

\begin{abstract}
The paper aims to analyze the Brazilian leading role in mediating with Iran in 2010, that would culminate with Tehran Declaration, through a study about Lula's Brazilian diplomacy. Through literature, documental and content review, it seeks to infer that: the Brazilian leading role in the case of mediating with Iran reflects both, rooted and typical patterns of Brazilian diplomacy ("accumulated history" for Amado Cervo, 2008), and the new factors, characterized in Lula's and Celso Amorim's own assertive external policy. The Tehran Declaration was only possible because of this combination of tradition and innovation that we can find in Lula's Brazilian diplomacy.
\end{abstract}

\section{KEYWORDS}

Tehran Declaration, Brazil, Iran. 